Supporting Information

\title{
The Effect of Al Distribution in MFI Framework Channels on the Catalytic Performance of Ethane and Ethylene Aromatization
}

\author{
Hua Liu, ${ }^{\dagger}$ Hui Wang, Ai-Hua Xing ${ }^{\dagger}$ and Ji-Hong Cheng ${ }^{*}$. \\ ${ }^{\dagger}$ National Institute of Clean-and-Low-Carbon Energy, Beijing 102211, China
}

${ }^{\$}$ NICE America Research, Inc., Mountain View, California 94043. United States 


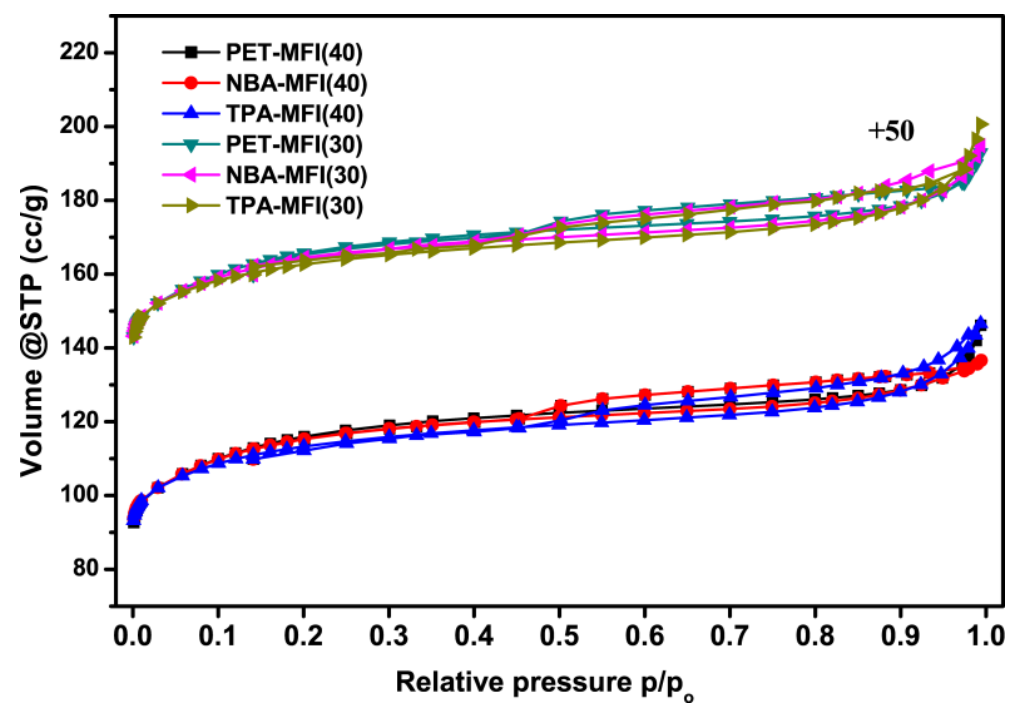

Figure $\mathbf{S 1} \mathrm{N}_{2}$ adsorption-desorption isotherms of the ZSM-5 samples at $77 \mathrm{~K}$. 

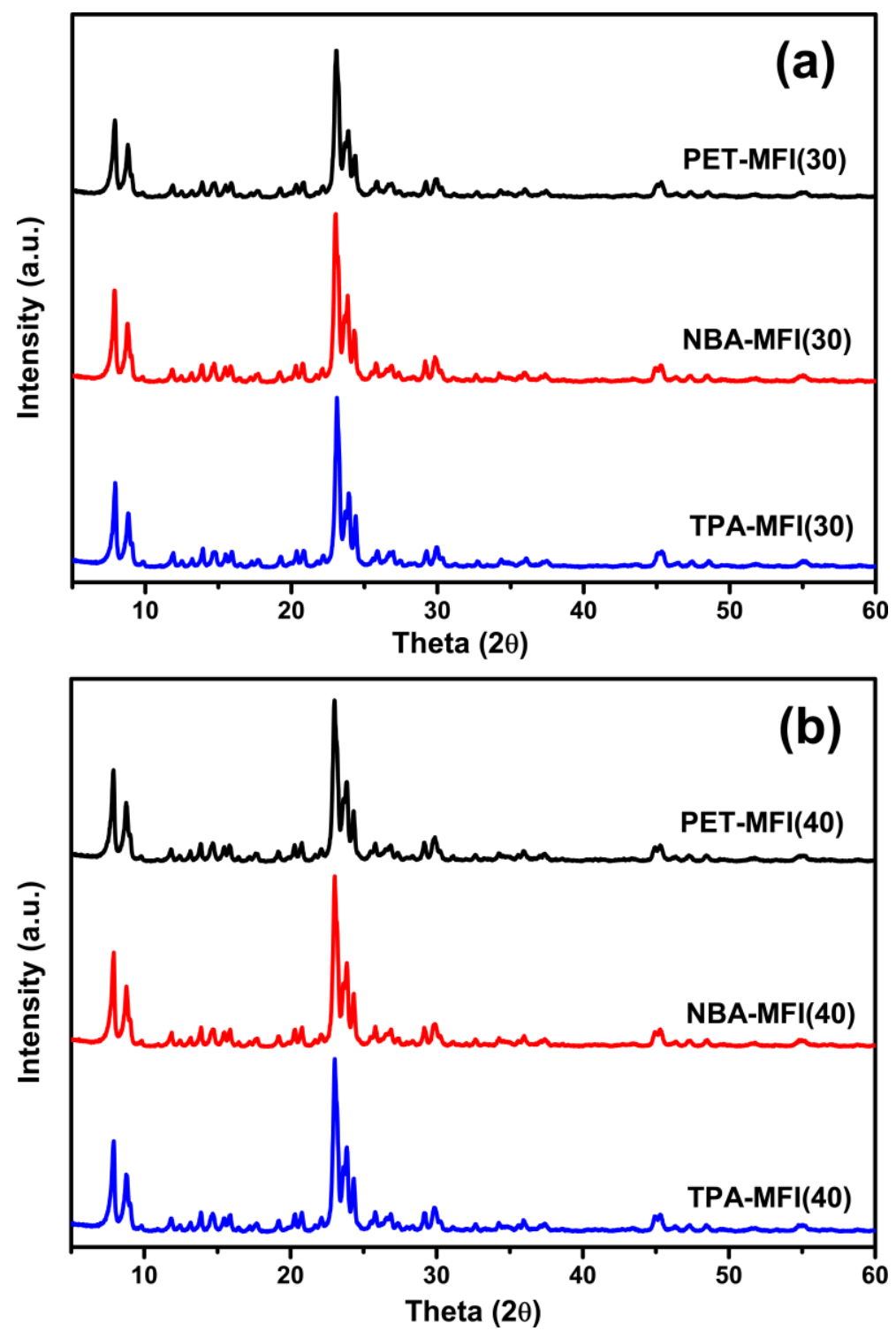

Figure S2 Powder XRD patterns of the ZSM-5 samples with $\mathrm{Si} / \mathrm{Al}_{2}$ of 30 (a) and $\mathrm{Si} / \mathrm{Al}_{2}$ of $40(\mathrm{~b})$. 

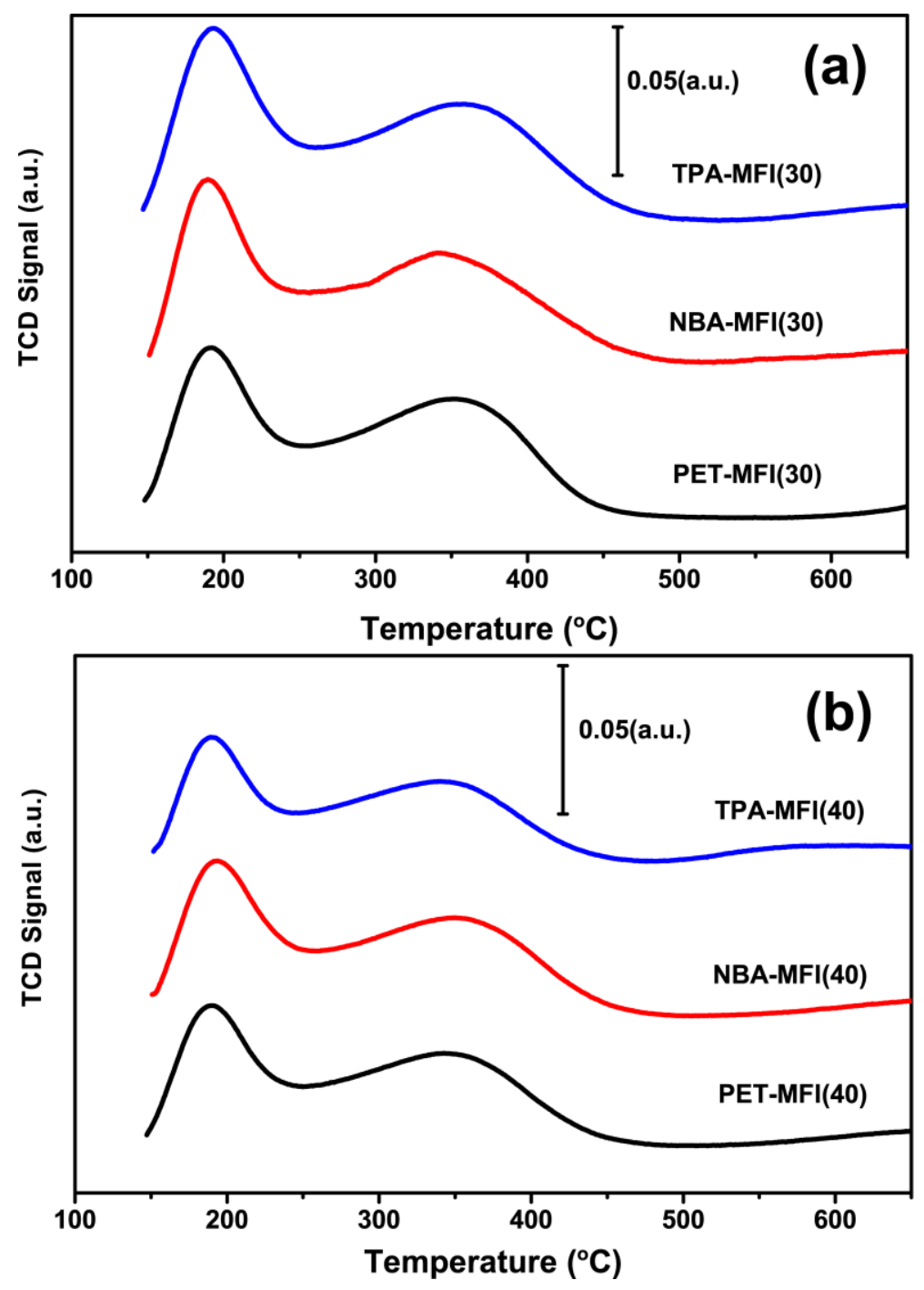

Figure $\mathrm{S3} \mathrm{NH} \mathrm{NH}_{3}$-TPD curves of ZSM-5 samples with $\mathrm{Si} / \mathrm{Al}_{2}$ of 30 (a) and $\mathrm{Si} / \mathrm{Al}_{2}$ of (b). 

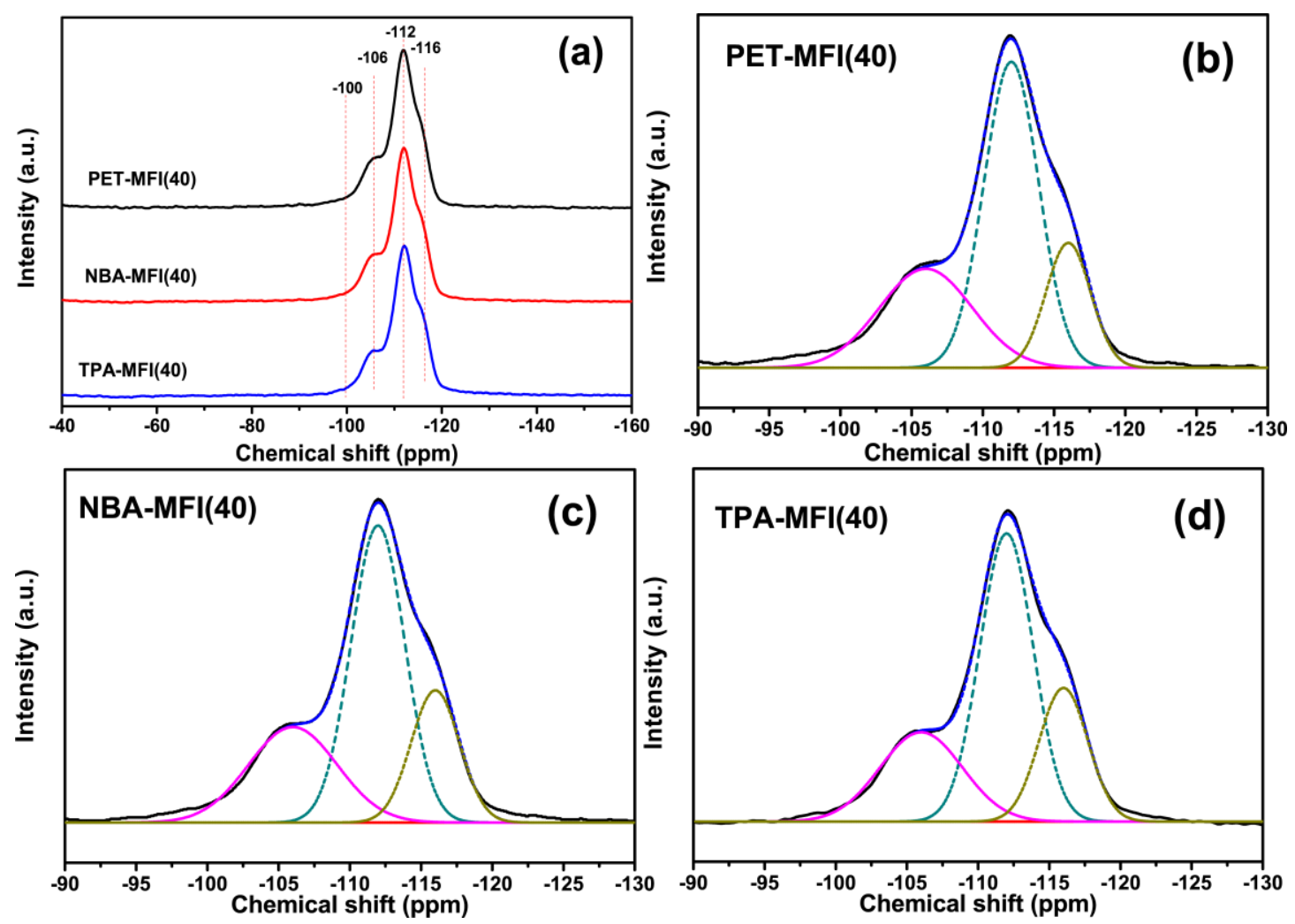

Figure $\mathbf{S 4}{ }^{29} \mathrm{Si}$ MAS NMR spectra of (a) $\mathrm{NH}_{4}$-type ZSM-5 zeolites with $\mathrm{Si}_{\text {/ }} \mathrm{Al}_{2}$ of 40 and its corresponding curve fittings of (b) PET-MFI(40), (c) NBA-MFI(40) and (d) TPA-MFI(40) 

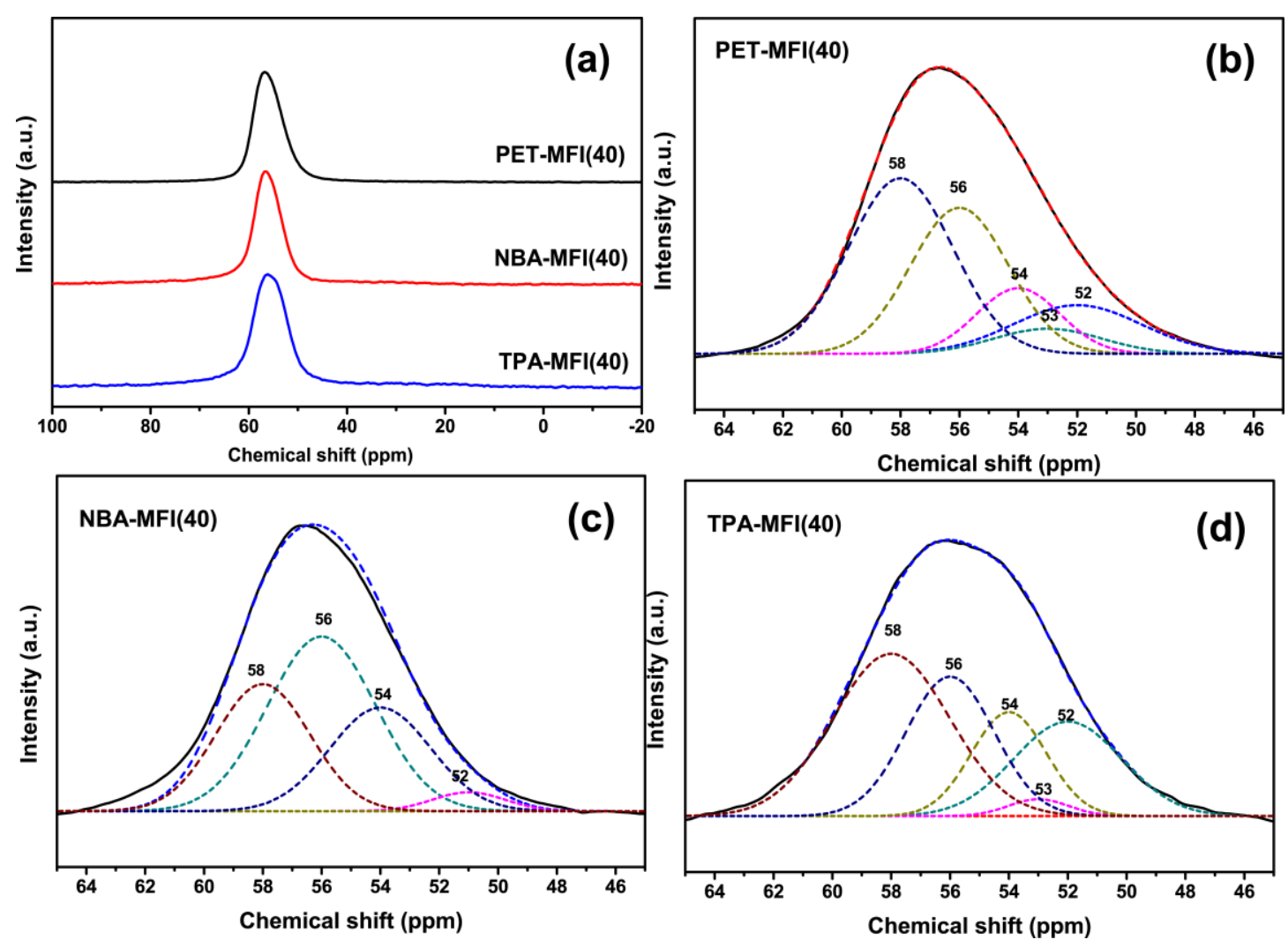

Figure S5 ${ }^{27} \mathrm{Al}$ MAS NMR spectra of (a) $\mathrm{NH}_{4}$-type ZSM-5 zeolites with $\mathrm{Si} / \mathrm{Al}_{2}$ of 40 and its corresponding curve fittings of (b) PET-MFI(40), (c) NBA-MFI(40) and (d) TPA-MFI(40)

Table S1 The dispersion of Pt.

\begin{tabular}{cccc}
\hline Catalyst & Pt loading $(w t \%)$ & $\begin{array}{c}\text { CO uptake } \\
\left(\mu \mathrm{mmol} / \mathrm{g}_{\mathrm{cat}}\right)\end{array}$ & Pt dispersion $(\%)$ \\
\hline Pt/PET-MFI(40) & 0.058 & 2.8 & 93 \\
Pt/NBA-MFI(40) & 0.048 & 2.3 & 92 \\
Pt/TPA-MFI(40) & 0.053 & 2.6 & 95 \\
\hline
\end{tabular}

